\title{
THE CENTRAL ARTERY OF THE RETINA* $†$ II. A STUDY OF ITS DISTRIBUTION AND ANASTOMOSES
}

\author{
BY \\ SOHAN SINGH AND RAMJI DASS \\ Department of Anatomy, Government Medical College, Patiala, India
}

THERE is little unanimity regarding the distribution and anastomoses of the central artery of the retina. According to François and Neetens (1954, 1956) and François, Neetens, and Collette (1955), the central artery of the retina is completely devoid of branches, while according to Wolff (1939) and Behr (1935) it is free from branches only in its intraneural course. Magitot (1908), Quain (1909), Beauvieux and Ristitch (1924), Wolff (1940), Bignell (1952), Wybar (1956), and Steele and Blunt (1956) on the other hand demonstrated branches from all parts of its course. Most investigators agree that this artery contributes to the blood supply of the optic nerve, but François and others $(1954,1955,1956)$ affirm that this is not the case.

The presence of a central artery of the optic nerve described by Behr (1935), Wolff (1939, 1954), François and others (1954, 1955, 1956), and Wybar (1956), is denied by Beauvieux and Ristitch (1924) and Steele and Blunt (1956).

Beauvieux and Ristitch (1924), Kershner (1943), François and others $(1954,1955,1956)$, and Steele and Blunt (1956) say there are no anastomoses between the central retinal and other arteries, but Vail (1948), Wybar (1956), and several other authors have observed and described them. The lamina cribrosa is the only site at which these anastomoses have been studied in any detail, and in this case too, contradictory views have been expressed.

In the present investigation the origin, course, distribution, and anastomoses of the branches of the central artery of the retina have been studied to find an answer to the following questions:

(i) Is the central artery of the retina an end artery or a terminal artery, or is it well connected by anastomoses?

(ii) In the event of blockage of the central artery of the retina, can a collateral circulation be established to maintain the circulation?

* Received for publication March 3, 1959.

$\dagger(i)$. A part of this paper is abridged from thesis accepted for the Master of Surgery Examination of the (ii). A part of this paper in abridged form was accepted for reading in the XVIII International Congress of
Ophthalmology in Brussels (Belgium), September 8-12, 1958 . 
(iii) What is the exact distribution of the central artery of the retina?

The material and methods used in this study have been described in a previous communication (Singh and Dass, 1960).

\section{Observations}

\section{Branches of the Central Artery of the Retina}

Branches, varying in size and number, were seen to arise from various parts of the central retinal artery (Fig. 1), and were not evenly distributed throughout its course.

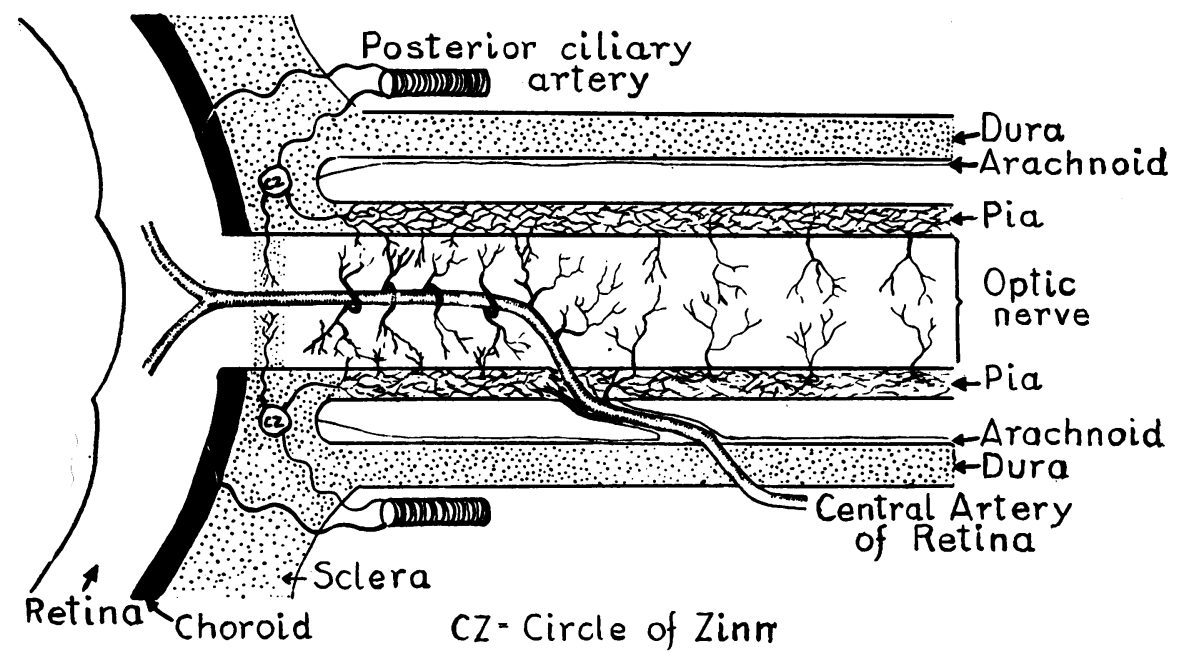

FIG. 1.-Schematic section of optic nerve and eyeball, showing course and branches of central retinal artery.

The incidence of such branches in 64 specimens, in which the artery was satisfactorily injected throughout its course, is shown in Table I.

TABLE I

ORIGIN OF BRANCHES FROM CENTRAL RETINAL ARTERY

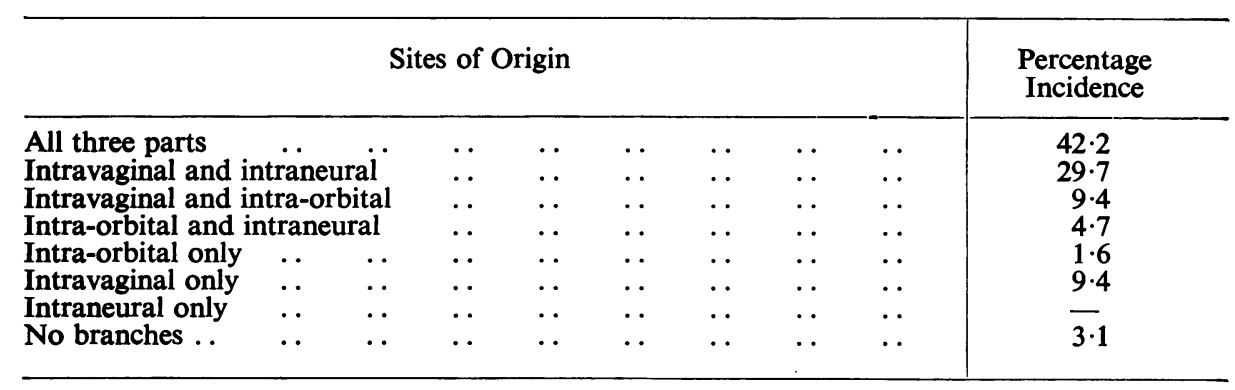


Number.-The branches which arose from the intra-orbital, intravaginal, and intraneural parts of the artery (Singh and Dass, 1960) are shown in Table II.

TABLE II

NUMBER OF BRANCHES FROM CENTRAL RETINAL ARTERY SEEN TO ARISE FROM THE THREE PARTS OF THE ARTERY

\begin{tabular}{|c|c|c|c|}
\hline \multirow{2}{*}{$\begin{array}{l}\text { Number of Branches } \\
\text { Observed }\end{array}$} & \multicolumn{3}{|c|}{$\begin{array}{c}\text { Percentage of Specimens Examined in which Branches from } \\
\text { Various Points were Seen }\end{array}$} \\
\hline & Intra-orbital & Intravaginal & Intraneural \\
\hline $\begin{array}{c}0 \\
1 \\
2 \\
3 \\
4 \\
5 \\
6 \\
7 \\
8 \\
\text { Uncertain } \dagger\end{array}$ & $\begin{array}{r}47 \cdot 8 \\
32 \cdot 6 \\
13 \cdot 0 \\
2 \cdot 2 \\
2 \cdot 2 \\
1 \cdot 1 \\
= \\
= \\
1 \cdot 1\end{array}$ & $\begin{array}{c}5 \cdot 3 \\
48 \cdot 7 \\
35 \cdot 5 \\
6 \cdot 6 \\
= \\
= \\
= \\
\overline{-}\end{array}$ & $\begin{array}{l}25 \cdot 0 \\
26 \cdot 6 \\
20 \cdot 3 \\
10 \cdot 9 \\
10 \cdot 9 \\
\overline{1 \cdot 6} \\
\frac{-}{1 \cdot 6} \\
3 \cdot 1\end{array}$ \\
\hline $\begin{array}{l}\text { Total No. of Specimens } \\
\text { Examined* }\end{array}$ & 92 & 76 & 64 \\
\hline
\end{tabular}

* Including all the latex-filled specimens and two serial reconstructions.

$\dagger$ These include those specimens which were distorted during maceration, so that the exact number and distribution of branches present could not be ascertained.

Site of Origin.-The branches from the intra-orbital part of the artery arose all along its course (Figs 2, 3, 4); those from the intravaginal part mostly arose from its distal half, particularly near its point of entry into the optic nerve (Figs 2, 3, 4, 5, 6, 20), and those from the intraneural part were evenly distributed (Figs 9, 10,11), except that there were very few from the distal third and more from the middle third of the horizontal section. No branches arose at the level of the lamina cribrosa.

Size.-Some branches were minute and some were as big as the central retinal artery itself. The size was unrelated to the number of branches given off in any one specimen.

Figs 2, 3, 4, 5 (opposite).-Origin, intra-orbital, and intravaginal course and the branches $(1,2$, $3,4)$ from these parts as seen from below.

Fig. 2 shows in addition the circle of Zinn. Fig. 3 was taken before the removal of the dural sheath. Here the sheath is semi-transparent because of its maceration in 20 per cent. HC1 (Singh and Dass, 1960), and all the pial branches are seen through the semi-transparent sheath. The branches from the central retinal artery are marked 1 (a, b, c, d), 2, 3, 4 .

The intraneural course of Fig. 5 is shown in Fig. 10. 


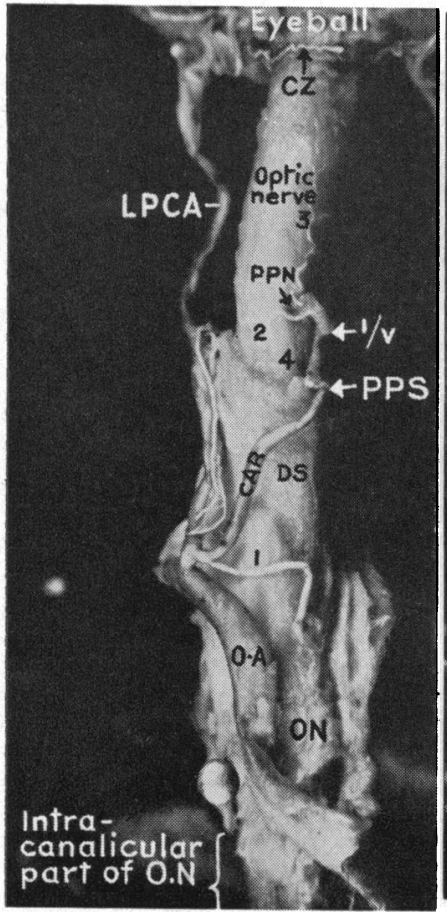

FIG. 2

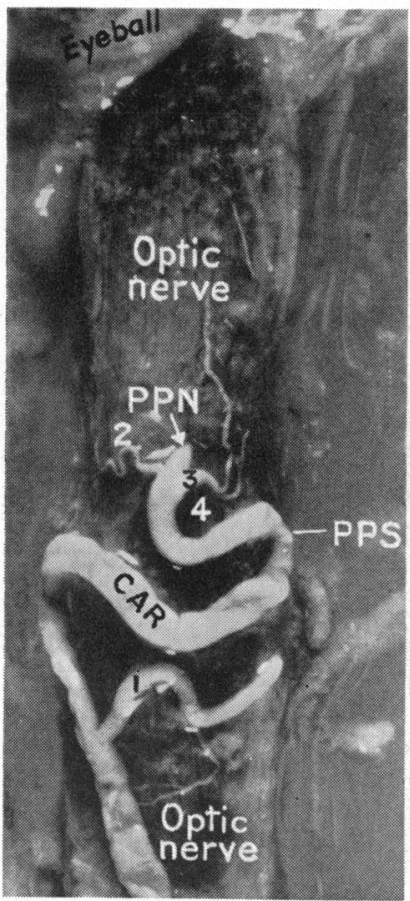

FIG. 4

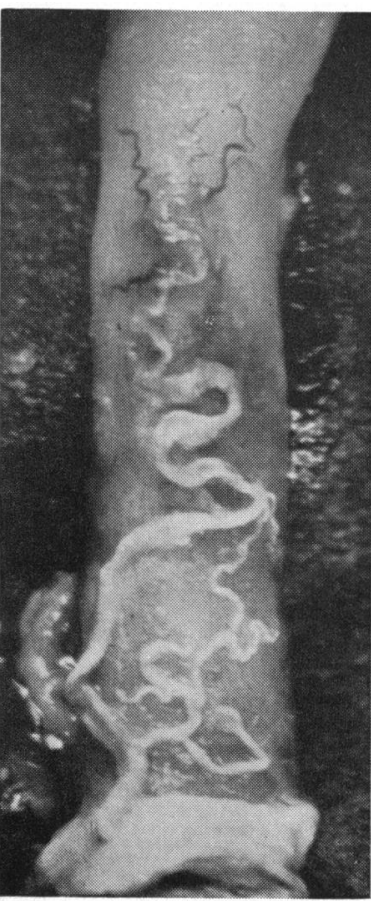

Fig. 3A

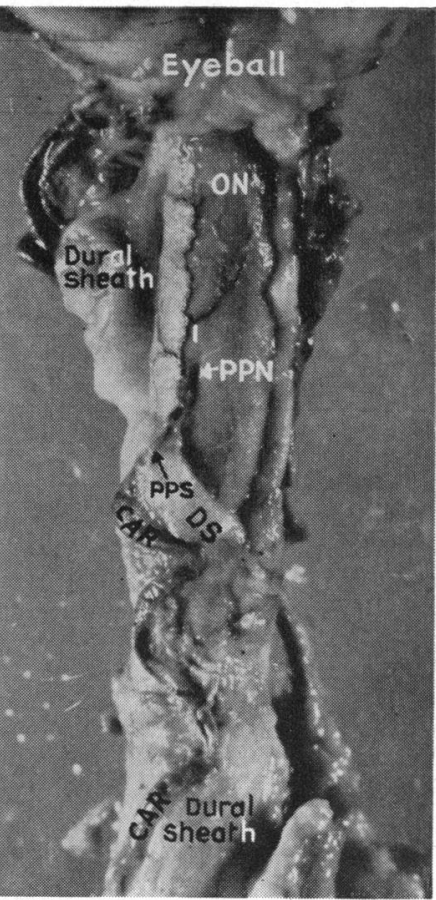

FIG. 5

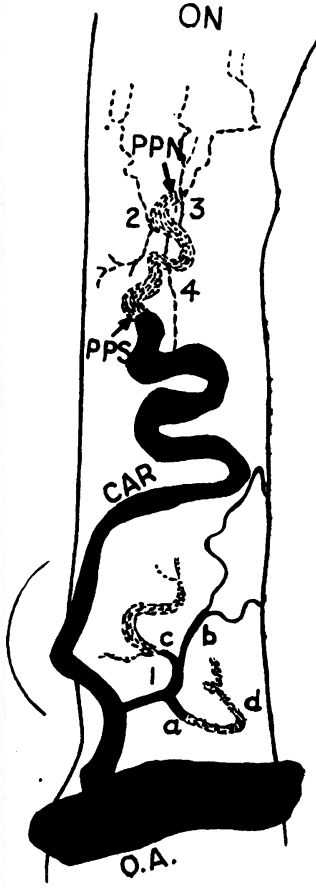

Artery lying on dura. .... Artery seen through dura.

Fig. 3B

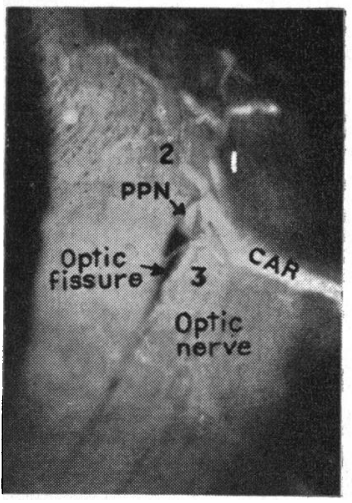

Fig. 6.-Intravaginal part of the artery and the branches $(1,2,3)$ from this part as seen from below after removal of the dural sheath. 


\section{Distribution}

(A) BRANCHES FROM THE INTRA-ORBITAL PART.-These were usually distributed to the dural sheath of the optic nerve, and about half of them penetrated the sheath to ramify on the pia of the optic nerve (Figs 2, 3, 4). In three specimens the branches entered the optic nerve substance to be distributed within the nerve. The area of the dural sheath and that of the nerve supplied varied, extending from the eyeball to the intra-canalicular part of the nerve. In 3.26 per cent. the branches penetrated the sheath at the level of the lamina cribrosa and behaved like short posterior ciliary branches.

(в) BRANCHES FROM THE INTRAVAGINAL PART.-These ramified on the pia covering the optic nerve (Figs 2, 3, 4, 5, 6, 7, 8, 16, 17, 18, 19, 20, 21, 23). In all cases these intravaginal branches ramified anterior to the point of entry of the artery into the nerve, and about half of them also ramified posterior to this point. The supply extended from the lamina cribrosa to various distances posterior to the point of entry. The area of the pia thus supplied is shown in Table III.

TABLE III

AREA OF PIA OF OPTIC NERVE SUPPLIED BY BRANCHES FROM THE INTRAVAGINAL PART OF THE CENTRAL RETINAL ARTERY

\begin{tabular}{|c|c|c|c|c|c|c|}
\hline \multicolumn{6}{|c|}{ Area Supplied } & \multirow{2}{*}{\begin{tabular}{|r|} 
Number of Specimens \\
11 \\
7 \\
14 \\
10 \\
2 \\
2 \\
26
\end{tabular}} \\
\hline $\begin{array}{l}\text { All round the nerve } \\
\text { Medial, lateral, and inferior aspects } \\
\text { Lateral and inferior aspects } \\
\text { Medial and inferior aspects } \\
\text { Lateral, inferior, and superior aspects } \\
\text { Lateral, inferior, and medial aspects } \\
\text { Inferior aspect only .. . . . . }\end{array}$ & $\begin{array}{l}\cdots \\
\cdots \\
\cdots \\
\cdots \\
\cdots \\
\cdots\end{array}$ & $\begin{array}{l}\cdots \\
\cdots \\
\cdots \\
\cdots \\
\cdots \\
\cdots \\
\cdots\end{array}$ & $\begin{array}{l}\cdots \\
\cdots \\
\cdots \\
\cdots \\
\cdots \\
\cdots\end{array}$ & $\begin{array}{l}\cdots \\
\cdots \\
\cdots \\
\cdots \\
\cdots \\
\cdots\end{array}$ & $\begin{array}{l}\cdots \\
\cdots \\
\cdots \\
\cdots \\
\cdots \\
\cdots\end{array}$ & \\
\hline \multicolumn{5}{|c|}{ Total Number of Specimens in which These Branches were Seen } & .. & 72 \\
\hline
\end{tabular}

From the pial branches of the intra-orbital, intravaginal, and rarely by the intraneural parts of the artery, twigs always passed radially into the optic nerve substance, travelling in the fibrous septa between the nerve fibres (Fig. 7). These twigs, which varied in size, penetrated the optic nerve substance for various depths (Fig. 1), frequently reaching the centre of the nerve (Figs 8,22). In one specimen a twig entering on the inferior aspect of the nerve pierced it and emerged from the superior surface to ramify on the pia and establish anastomoses. One to three stout twigs from the pial branches of the intravaginal part entered the optic nerve substance through the fissure on the under surface of the nerve (posterior 


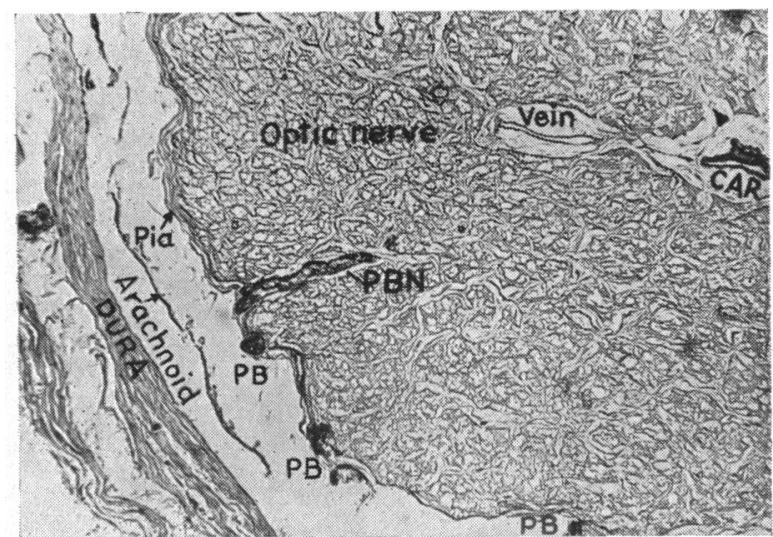

FIG. 7 ( $\times$ 27) pial branches (PB) with one of these entering the nerve radially $(\mathrm{PBN})$.

FIG. $8(\times 27)$ pial branches $(\mathrm{PB})$ with some branches derived from them running within the substance of nerve (PBN).

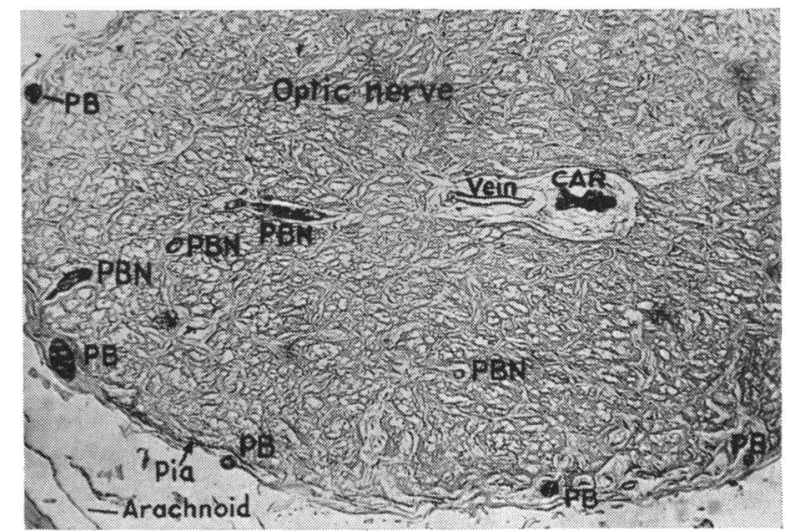

FIGs 7, 8.-Transverse sections of optic nerve, after injection of the central retinal artery with 3 per cent. prussian blue. Central retinal vessels are also seen lying in the centre of the nerve.

to the point of entry in seven specimens (Figs 20,22) and anterior to it in one). On reaching the centre of the optic nerve, these twigs behaved in various ways:

(i) In two specimens, the twigs divided into anterior and posterior branches running in the centre of the nerve for 3 to $4 \mathrm{~mm}$. in either direction.

(ii) In one specimen, radial branches were given off in the centre of the nerve with one branch travelling backwards in the centre of the nerve for 3 to $4 \mathrm{~mm}$.

(iii) In the remaining specimens, branches were given out into the nerve substance.

(c) BRANCHES FROM THE INTRANEURAL PART.-These ran radially as well as backwards and forwards (Figs 9, 10,11, overleaf) in the septa between the nerve bundles, reaching quite close to the pia in most specimens; in ten specimens they reached the pia to behave like pial branches (Fig. 10). 


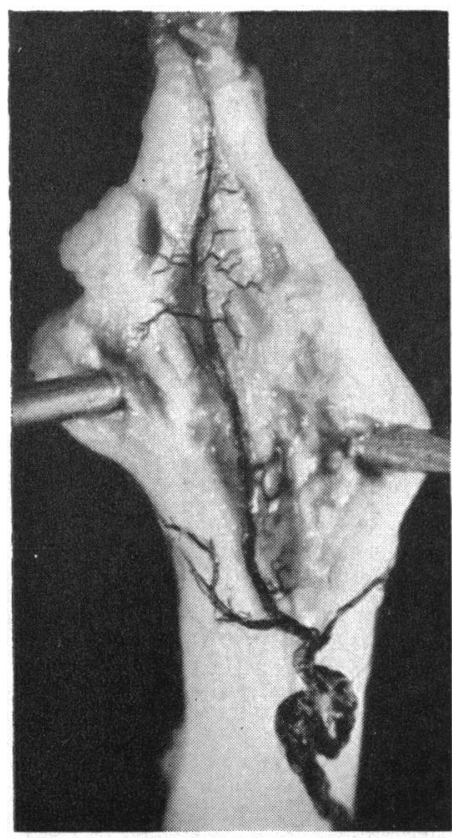

Fig. 9A

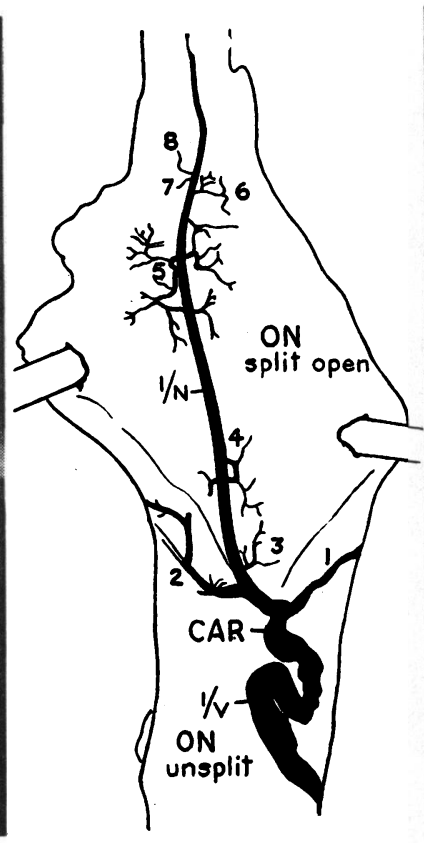

Fig. 9B

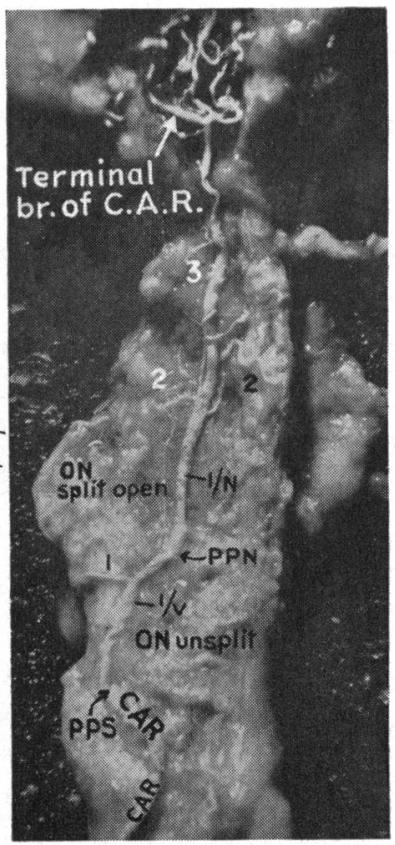

FIG. 10

Figs 9, 10.--Intravaginal and intraneural course and branches from them $(1,2$ from the intravaginal part and $3,4,5,6,7,8$ from the intraneural part in Fig. 9), as seen from below on splitting open the optic nerve anterior to the site of penetration.

In Fig. 10 terminal parts of many intraneural branches $(2,2,3)$ were seen to ramify on the pia. The terminal branches were full of aneurysmal dilatations throughout.

In six specimens, one of the intraneural branches [arising either from the vertical intraneural part (five specimens; Fig. 11), or from the fourth bend* (one specimen)] divided into two to run forwards and backwards in the centre of the nerve. These branches did not exceed 3 to $4 \mathrm{~mm}$. in length, except for one specimen which was $6 \mathrm{~mm}$. long, and ran for threequarters of the total length of the intraneural horizontal part of the artery. In this type of ramification the posterior branch was usually much smaller than the anterior branch. These intraneural branches gave out radial branches to supply the optic nerve, and sometimes the main branch gave off additional radial branches besides the anterior and posterior central branches first described. In one specimen an intraneural branch also gave off pial branches.

In one specimen of this series, a retinal branch arising from the middle of the horizontal section of the intraneural part of the artery, ran forwards in the centre of the nerve to enter the eyeball with the central retinal artery at the optic disc. This branch supplied the supero-medial part of the retina.

* See Singh and Dass (1960). 

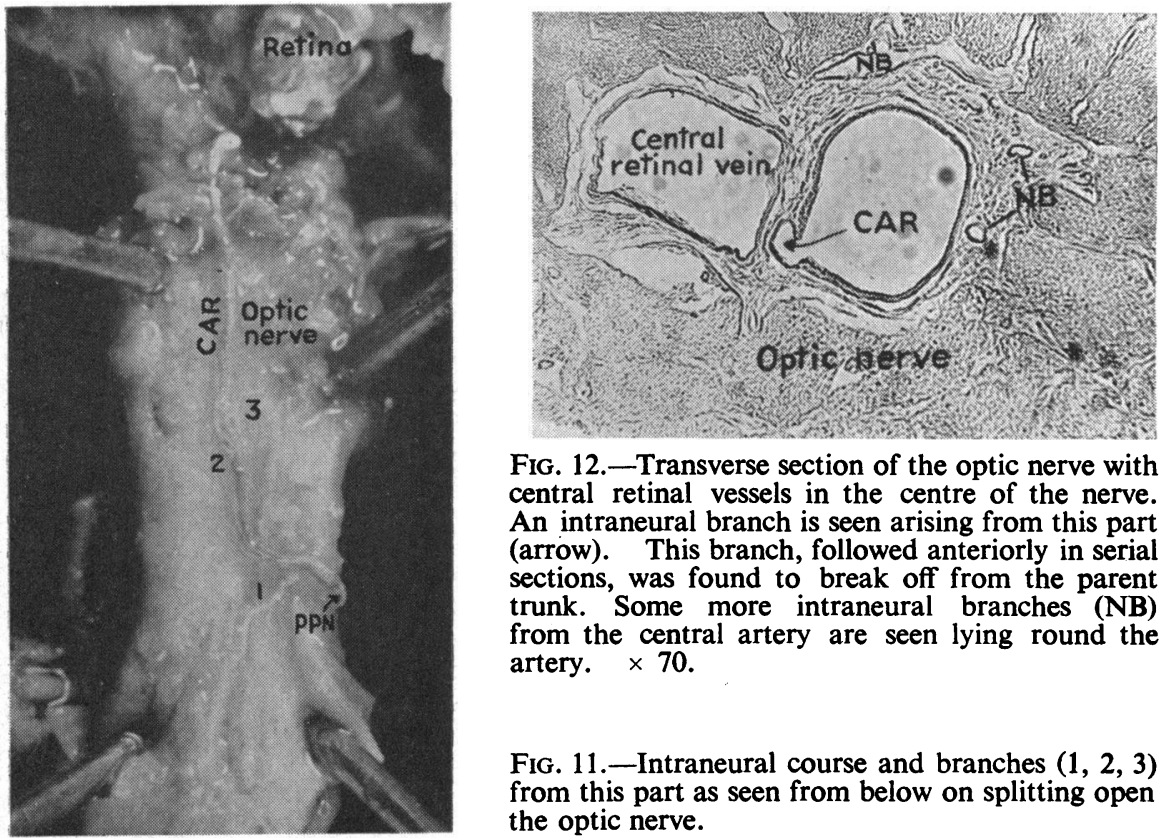

FIG. 12.-Transverse section of the optic nerve with central retinal vessels in the centre of the nerve. An intraneural branch is seen arising from this part (arrow). This branch, followed anteriorly in serial sections, was found to break off from the parent trunk. Some more intraneural branches (NB) from the central artery are seen lying round the artery. $\times 70$.

Fig. 11.-Intraneural course and branches $(1,2,3)$ from this part as seen from below on splitting open the optic nerve.

A transverse section showing the origin of an intraneural branch is seen in Fig. 12.

The origin of the central retinal artery and branches from it are further illustrated by the casts shown in Figs 13, 14, and 15 (overleaf).

\section{Anastomoses Established by the Central Artery of the Retina}

Numerous anastomoses were established by the branches of the central retinal artery with other branches of the ophthalmic artery. However, no anastomoses were seen at the lamina cribrosa as no branch was given by the central artery in this region. Most of these anastomoses were seen on the pia of the optic nerve, and occurred between the pial branches of the central retinal artery and pial branches from other sources (Figs 16, 17, 18, 19, 21, 23 , overleaf). The pial branches of the central artery almost always arose from the intravaginal part, a few arose from the intra-orbital part and fewer still from the intraneural part. These pial branches most frequently anastomosed with the recurrent pial branches of the circle of Zinn * (Figs 1, 16, 17, 18, $19,21)$, and with pial branches from the collateral branches of the ophthalmic

\footnotetext{
* A ring of vessels situated in the sclera around the entrance of the optic nerve which is formed
} by twigs from posterior ciliary arteries (Figs 1, 2, 17, 18). 


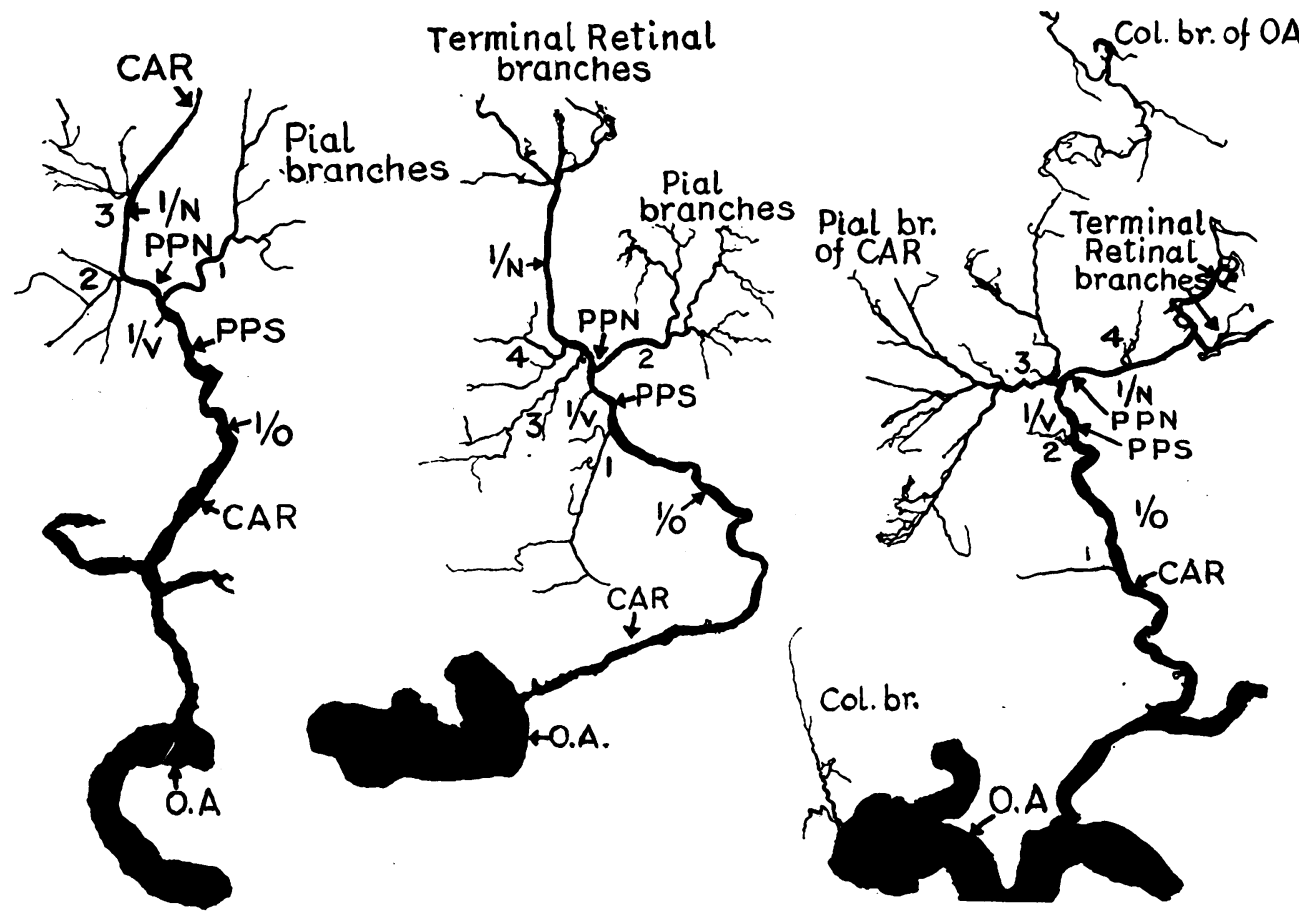

Figs $13,14,15$.-Casts of central artery of retina showing its origin and branches $(1,2,3,4)$ from the various parts.

Fig. 15 shows anastomosis between the pial branch of the central retinal artery and a collateral branch from the ophthalmic artery (see below).

artery (Figs 16, 17, 18, 19, 21, 23). The various pial branches of the central artery at times anastomosed with one another. These anastomoses were most commonly situated on the inferior aspect of the nerve and less commonly on the superior, medial, or lateral aspects or all round the nerve. They were usually anterior to and sometimes posterior to the site of entry of the central retinal artery into the nerve.

Rarely anastomoses were also established within the substance of the optic nerve between intraneural branches of the central retinal artery and intraneural branches which arose from the recurrent pial branches of the circle of Zinn, the intravaginal part of the central artery, or the collateral branches of the ophthalmic artery (Fig. 1).

In one specimen, an intra-orbital branch of the central retinal artery anastomosed on the dural sheath with a small lateral posterior ciliary artery which arose from the ophthalmic artery distal to the central retinal artery.

Thus the intravaginal branches of the central artery established anastomoses much more frequently than those from the other two parts of the artery. 


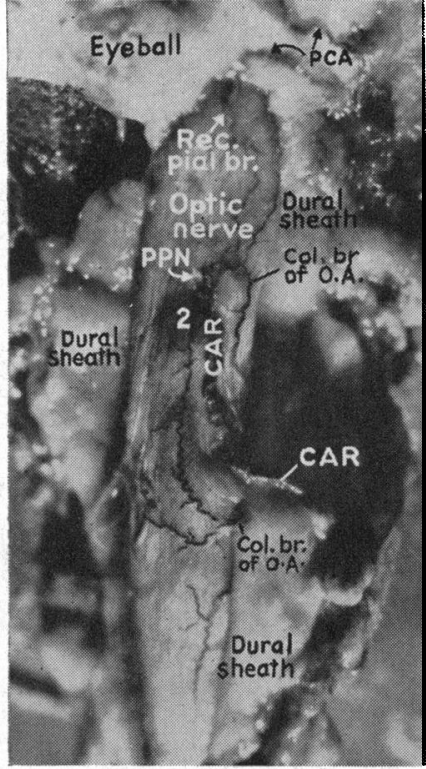

FIG. 16.-Intravaginal course with a branch (2) arising from this part, showing its anastomoses with collateral branches from the ophthalmic artery and recurrent pial branches of circle of Zinn, as seen from below on reflection of the dural sheath.
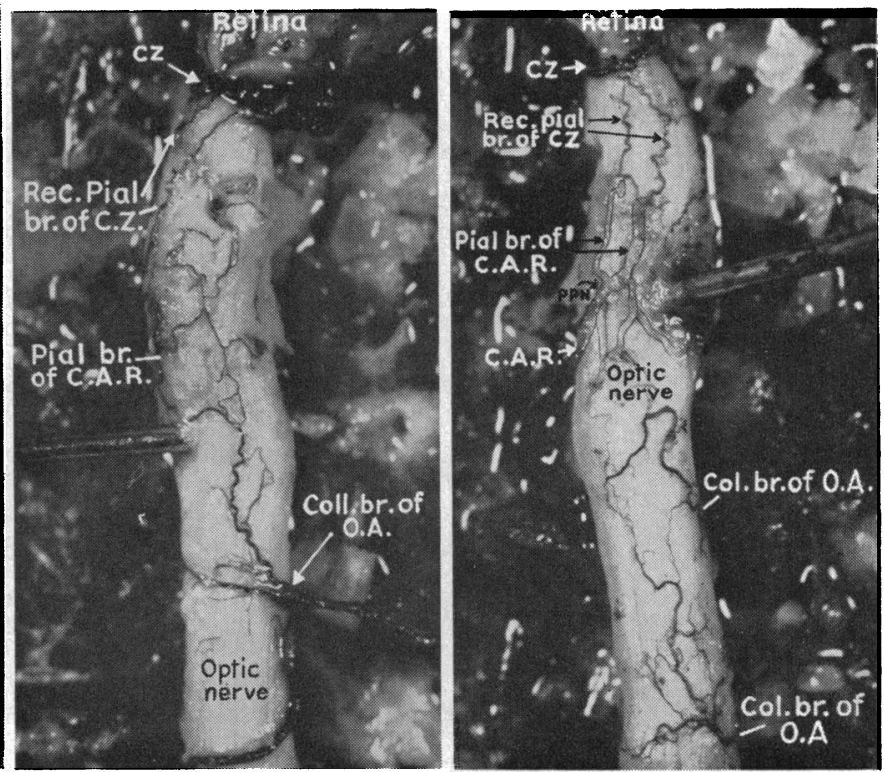

FIGs 17, 18.-Two views of the same specimen, showing branches arising from the intravaginal part and anastomoses established by them as seen from above (Fig. 17) and below (Fig. 18) after removal of the dural sheath. There are anastomoses with pial branches of collateral branches from the ophthalmic artery and with recurrent pial branches of the circle of Zinn. Fig. 18 is slightly retouched to show clearly the branches of the central artery.

The size of these anastomoses can be judged from the following observations :

(1) In one specimen, the ophthalmic artery was injected with red latex after its third part and the central retinal artery and other main branches had been ligated near their origin, the collateral branches going to the optic nerve being left intact. The red latex filled the intra-orbital part of the central artery from its intravaginal part, i.e. from the distal to the proximal. Blue latex was then injected into the central artery, and on dissection the meeting of the red and blue latex in various channels demonstrated the sites of the anastomoses (Figs 19, 20, 21, 22, overleaf).

(2) In another specimen, the order of injection was reversed; the central artery being injected first and the ophthalmic artery second. Similar results were obtained (Fig. 23, overleaf).

In these two experiments, the latex reached the central retinal artery through anastomoses between its own pial branches and the pial branches of collaterals of the ophthalmic artery. 

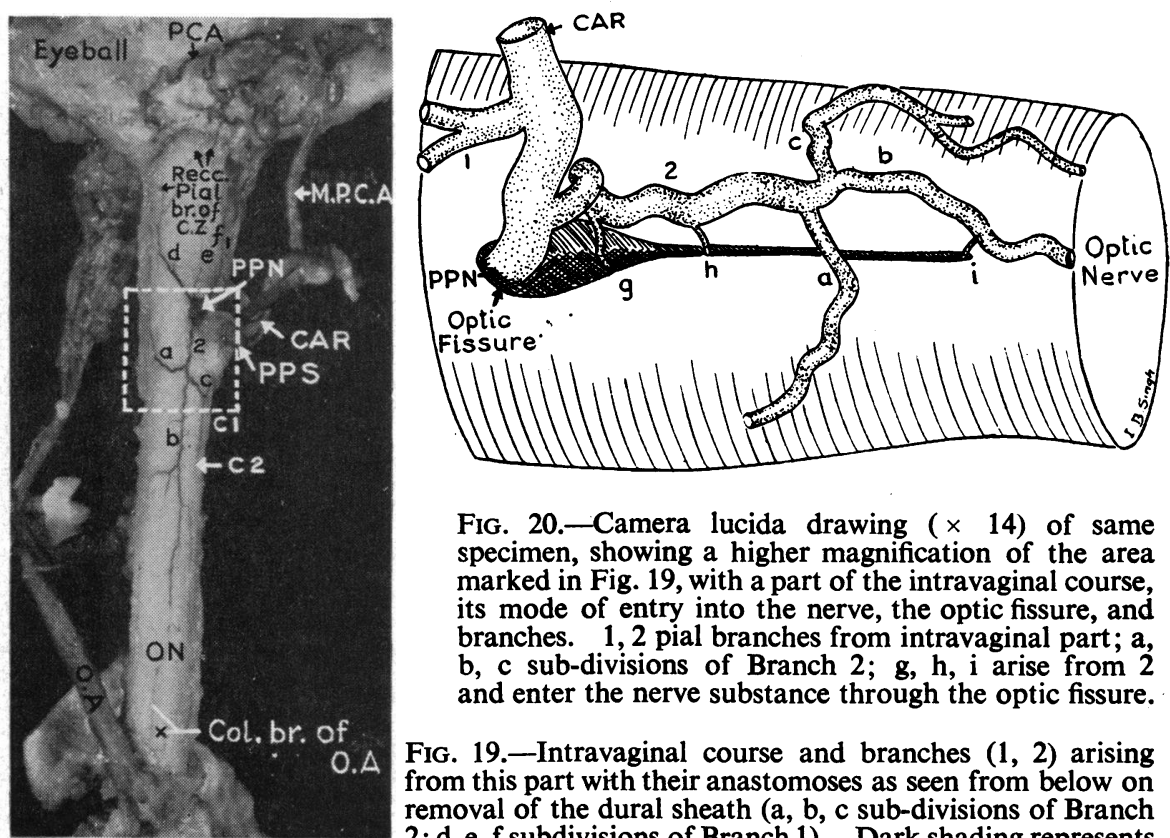

FIG. 20.-Camera lucida drawing $(x 14)$ of same specimen, showing a higher magnification of the area marked in Fig. 19, with a part of the intravaginal course, its mode of entry into the nerve, the optic fissure, and branches. 1,2 pial branches from intravaginal part; $a$, $\mathrm{b}$, c sub-divisions of Branch $2 ; \mathrm{g}, \mathrm{h}$, $\mathrm{i}$ arise from 2 and enter the nerve substance through the optic fissure.

FIG. 19.--Intravaginal course and branches $(1,2)$ arising from this part with their anastomoses as seen from below on removal of the dural sheath $(a, b, c$ sub-divisions of Branch $2 ; \mathrm{d}, \mathrm{e}, \mathrm{f}$ subdivisions of Branch 1 ). Dark shading represents blue latex and light shading represents red latex showing the anastomoses between the two trunks.

(3) In four more specimens fluid was injected into the central artery alone, and the posterior ciliary arteries were seen to fill from the eyeball side via anastomoses between the pial branches of the central retinal artery and the recurrent pial branches of the circle of Zinn.

All these observations lead to the conclusion that the anastomoses were sufficiently large to allow fluid to pass from one channel to another. These anastomoses were usually visible to the naked eye.

\section{Discussion}

The central artery of the retina, though of vital importance, has been the subject of much controversy. Classical investigations in this field, which include those of Beauvieux and Ristitch (1924), Wolff $(1939,1954)$, François and others (1954, 1955, 1956), Wybar (1956), and Steele and Blunt (1956), do not seem to agree with each other. Much of this confusion seems to be due to attempts to cover endless variations by rigid and dogmatic statements. Moreover, the number of specimens examined in each series has been rather small. The present investigation of 106 specimens showed that no two examples (even from the two eyes of the same person) wholly agreed in their pattern of origin, course, branches, distribution, and anastomoses, this means that any dogmatic ruling is likely to lead to error.

It is also necessary to remember that the results depended upon the efficiency 


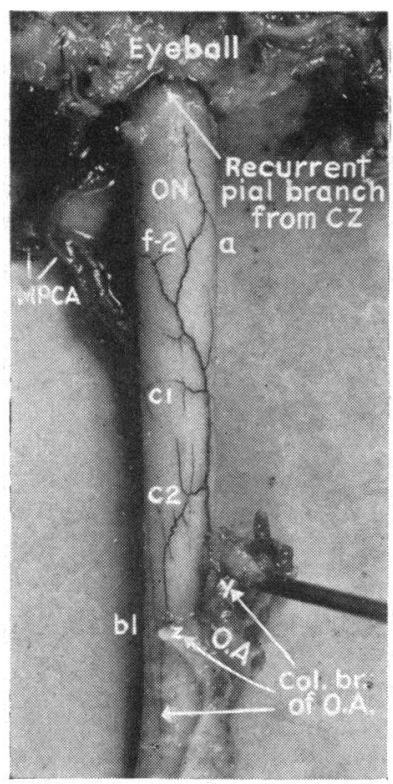

Fig. 21.-Same specimen from above, showing pial branches $(1,2)$ from intravaginal part, with subdivisions $a, b, c$, f. Collateral branches of ophthalmic artery $y, z$.

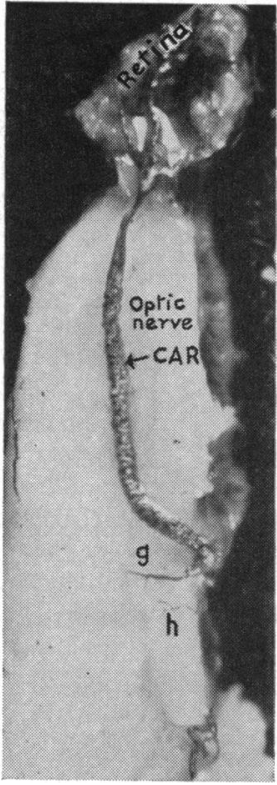

Fig. 22.-Intraneural course of same vessel. $g, h, i$, arise from Branch 2.

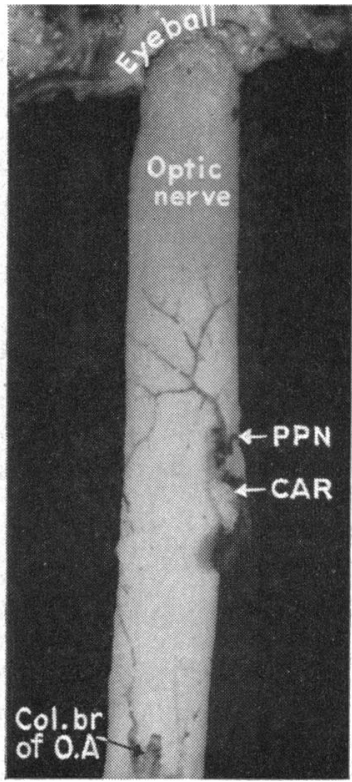

FIG. 23.-Intravaginal course and pial branches from this part, including anastomoses with collateral branches of the ophthalmic artery as seen from the lateral side of nerve after the removal of the dural sheath.

and completeness of the injection. The pressure must be high enough to inject the smallest vessels and these have to be efficiently cleared of blood clots by irrigation with water. Because of these technical difficulties the observations regarding the finer branches and anastomoses can hardly be submitted to a statistical analysis. More reliance is to be placed on positive than upon negative findings, as pointed out by Wybar (1956) and by Steele and Blunt (1956).

\section{Branches of the Central Retinal Artery}

Most workers have paid their main attention to these branches, but there is little agreement between them.

Central Collateral Retinal Artery.-The site of origin, course, distribution, and anastomoses of the central collateral retinal branch of the central retinal artery has been described by many workers (Kuhnt, 1879; Behr, 1935; Wolff, 1939, 1954; François and Neetens, 1954, 1956; François, Neetens and Collette, 1955; and Wybar, 1956). On reaching the centre of the optic nerve this branch is said to divide into two branches-one running forwards to the region of the lamina cribrosa and the other backwards to reach the 
optic foramen. These branches in the centre of the optic nerve have been given different names by different authors:

"Arteriae collaterales centralis retinae" (Wolff, 1939, 1954);

"Anterior and posterior optic nerve arteries" (Behr, 1935);

"Central artery of the optic nerve".(François and others, 1954, 1955, 1956).

The site of origin of this collateral branch has been described as follows:

(i) From the ophthalmic artery proximal to the origin of the central artery of retina (François and Neetens, 1954).

(ii) From the central retinal artery:

(a) As it pierces the dural sheath of the optic nerve (Wolff, 1939).

(b) As it pierces the optic nerve to go to its centre (Wybar, 1956). The two branches may arise separately or from a common stem.

(c) As it bends in the centre of the optic nerve (Behr, 1935, cited by Kershner, 1943).

Wybar (1956) could not trace these central branches in their entire length as did other workers.

Wolff (1939) and certain other authors said that this branch was constant, but this was denied by Steele and Blunt (1956).

None of the specimens in the present series showed a typical central artery of the optic nerve conforming to the description given above, but in eight a minor representation of this artery was seen. The length of the anterior and posterior optic nerve arteries is very variable, the anterior being usually longer and the posterior much shorter. Unlike the descriptions given by some authors, these were seen to run in each direction for 3 to $4 \mathrm{~mm}$., except that one anterior branch ran forwards for $6 \mathrm{~mm}$. These branches did not reach the lamina cribrosa or the optic foramen in any specimen. They arose from the intravaginal part in two specimens, from the vertical section of the intraneural part in five (Fig. 11), and from the fourth bend of the central retinal artery in one. Thus the occurrence as well as the course of this collateral artery is both inconstant and variable.

In seven specimens of the present series only one branch, either anterior or posterior, was present, the site of origin being as follows:

(i) From the intravaginal part of the central retinal artery in one specimen.

(ii) From the vertical section of the intraneural part in three specimens.

(iii) From the bend in the centre of the optic nerve in one specimen.

(iv) From the horizontal section of the intraneural part in two specimens. 
The branches indicated under (i), (ii), and (iii) ran backwards in the centre of the nerve for 2 to $3 \mathrm{~mm}$.; while those indicated under (iv) ran forwards, one of them entered the eyeball at the optic disc to supply the superomedial aspect of the retina.

Branches from the Intra-orbital and Intravaginal Parts of the Central Retinal Artery.-These extraneural branches are not adequately described in the literature. According to François and Neetens $(1954,1956)$ and François, Neetens, and Collette (1955), the central retinal artery gives off no significant branches in its entire course. Traquair (1949), Bignall (1952), and Wybar (1956) observed branches from these parts but gave no further details about their number and site of origin.

One branch that may arise from this part is the "central collateral retinal artery" described above; Beauvieux and Ristitch (1924) have also described a collateral branch, but theirs was not the same as the collateral branch described above, and did not reach the centre of the optic nerve [as wrongly quoted by Wybar (1956) and François and Neetens (1954)] even though the site of origin was the same as that described by Wolff (1939) for the central collateral retinal artery. It runs beside the central retinal artery in the subarachnoid space, ends on the pia of the optic nerve, where it behaves like a pial vessel and sends small branches to the interior of the optic nerve for a distance of 5 to $6 \mathrm{~mm}$. anterior to the point of entry of the central artery into the nerve. These branches supply only the inferior surface of the optic nerve. This formation was seen in two out of the three specimens examined by Beauvieux and Ristitch (1924); they quote Magitot as having observed this branch in one out of six cases examined by him, and also state that Vossius had described such a branch. Wolff (1939) mentioned branches which arose from the intra-orbital part of the central artery, pierced the dural sheath of the optic nerve, and behaved like pial vessels. In fifteen specimens, Steele and Blunt (1956) found that the origin of such branches was close to the point of penetration of the central retinal artery into the optic nerve.

In the present series, the number, site of origin, size, and distribution of branches from the intra-orbital part of the artery were studied in 92 specimens and those from the intravaginal part in 76 specimens. They varied in number from nil to five and three respectively (Table II), and were usually seen to contribute to the blood supply of the optic nerve, The site of origin and distribution are described at length above.

Branches from the Intraneural Part of the Central Retinal Artery.-According to François and others $(1954,1955,1956)$ and Wolff (1939), the intraneural part gives off no branch whatsoever. François, Neetens, and Collette (1955) further stated that any branch in the region of the lamina cribrosa or behind it reached and supplied the retina and not the optic nerve. In the present 
series, however, branches were seen to arise from this part of the artery in 75 per cent. of specimens.

(i) Capillary branches arising in the region of the lamina cribrosa have been described by Nettleship (1876), Leber (1903), Coats (1905), Gonin (1905), Parsons (1906), Quain (1909), Rochon-Duvigneaud (1933), Wolff (1940), Igersheimer (1942), Duke-Elder (1946), Traquair (1949), Wexler (1950), and Wybar (1956).

Wolff (1940), Igersheimer (1942) and Wybar (1956) claimed that these were the only branches arising from the intra-neural part of the central retinal artery. Branches from this region were not observed by Beauvieux and Ristitch (1924), Behr (1935), Kershner (1943), Bignell (1952), François and others $(1954,1955,1956)$, or Steele and Blunt (1956), nor were any such branches seen in the present series either in dissections or in serial sections.

(ii) Recurrent branches backwards in the centre of the optic nerve as far as the optic foramen ( $c f$. central collateral retinal artery) were described by Quain (1909), Magitot (1908), Whitnall (1932), and Abbie (1938). Branches of this type were seen in the present series in only four specimens, and these differed from the recurrent branches described in that they did not reach the optic foramen and were small.

Duke-Elder (1946) described recurrent branches but did not specify whether they were in the central position. Branches running backwards in the optic nerve for various distances and supplying it were seen in twenty specimens in the present series, but none of these reached the optic foramen.

(iii) Duke-Elder described small twigs leading anteriorly up to the lamina cribrosa. In the present series branches supplying the optic nerve, between the lamina cribrosa and the point of entry of the central artery, were seen in 43 specimens, but they did not reach the level of the lamina cribrosa. In one specimen a branch of this type reached the retina and contributed to the supply.

(iv) One branch which arises from this part of the central retinal artery is the central collateral retinal artery, and this is fully described above.

Branches arising from this part of the central artery, running radially in the optic nerve and sometimes reaching right up to the pia have been described by Beauvieux and Ristitch (1924)*. According to Leber (1903), all the branches given off by the intraneural part of the artery are radial in direction, but Magitot (1908) said that they ran antero-posteriorly parallel

* Francois and Neetens (1954), Wybar (1956), and Steele and Blunt (1956) wrongly quote Beauvieux and Ristitch 1924) as saying that there are no branches from the intraneural part. 
with the axis of the optic nerve. Beauvieux and Ristitch (1924) stated that these branches ran longitudinally in the nerve for $1.5 \mathrm{~mm}$. before assuming a radial direction, some reaching the pia on the inferior aspect of the optic nerve to ramify on it, so that small branches penetrated radially towards the centre of the nerve. Wybar (1956) also described the existence of these branches, some of which terminated in the nerve while others anastomosed with branches from the arterial plexus of the pia. In the present investigation, branches from the intraneural part were seen to run radially as well as forwards and backwards, so that it was difficult to assign to them any one particular pattern. They ran in the optic nerve in the septa between the various nerve fibres and sometimes reached the pia or terminated close to it. They also ran forwards or backwards to supply the region of the optic nerve both anterior and posterior to the point of entry of the central retinal artery into the optic nerve. In one specimen a branch arising from the middle of the intraneural horizontal section of the central artery supplied the superomedial part of the retina.

Steele and Blunt (1956), describing branches from the intraneural part of the artery in nine specimens, observed seven cases in which one branch arose near the middle of the intraneural part, while two branches were seen in each of the other two.

According to Beauvieux and Ristitch (1924), the number of branches arising from the intraneural part may vary from one to five. In the present series of 64 specimens, the number of intraneural branches varied from nil to eight (Table II), and they arose anywhere along the intraneural part except at the lamina cribrosa.

\section{Anastomoses of the Central Retinal Artery}

Anastomoses between branches of the central retinal artery and those of various other arteries have been described by many workers, but were not observed by Beauvieux and Ristitch (1924), Behr (1935), Kershner (1943), François and others $(1954,1955,1956)$, or Steele and Blunt (1956). According to François and others $(1954,1955,1956)$ the central retinal artery gives off no branches at all and hence the question of anastomoses does not arise. Beauvieux and Ristitch (1924) considered the branches of the central retinal artery to be end arteries.

The various sites at which anastomoses have been described are as follows:

(i) With the Circle of Zinn in the Region of the Lamina Cribrosa.-These have been described by Nettleship (1876), Leber (1903), Coats (1905), Gonin (1905), Parsons (1906), Quain (1909), Rochon-Duvigneaud (1933), Wolff (1940), DukeElder (1946), Vail (1948), Traquair (1949), Igersheimer (1942), Wexler (1950), and Wybar (1956). Duke-Elder (1946) and Traquair (1949) stated that this was the only site at which the central retinal artery established anastomoses.

Nettleship (1876), Leber, (1903), Parsons (1906), and Rochon-Duvigneaud (1933) have described these as purely capillary anastomoses, which would be 
insufficient to establish any circulation in the event of blockage of the central artery and hence of little physiological importance. Coats (1905) and Gonin (1905), however, remarked that these capillary anastomoses would dilate sufficiently to assist circulation should the central artery be blocked.

Sautter and Seitz (1952), after injecting vital dye intravenously into the rabbit in vivo, found that it passed from the central artery into the circle of Zinn through these anastomotic channels.

The existence of anastomoses at this site was, however, denied by Magitot (1908), Beauvieux and Ristitch (1924), Behr (1935), Wolff (1939), Kershner (1943), Bignell (1952), François and Neetens (1954, 1956), François and others (1955), and Steele and Blunt (1956). Magitot (1908) explained this absence on the ground that the central artery did not supply tissues of mesodermal origin (lamina cribrosa), but only the nervous membrane of the eye. However, Beauvieux and Ristitch (1924), Behr (1935), Wolff (1939), Kershner (1943), Bignell (1952), François and others $(1954,1955,1956)$, and Steele and Blunt (1956) explained the absence of these anastomoses on the ground that no branches were given out by the intraneural part of the central artery in this region.

In the present series, no anastomoses were seen at this site, and no discoloration of the region of the lamina cribrosa was seen on serial sectioning after injecting prussian blue solution into the central retinal artery.

(ii) With the Choroidal Arteries.-Nettleship (1876), Leber (1903), Coats (1905), Gonin (1905), Parsons (1906), Quain (1909), and Rochon-Duvigneaud (1933) described anastomoses of the central retinal artery with the choroidal arteries, which were more direct than those at the circle of Zinn. According to these authors anastomoses occur only at these sites apart from those at the region of the lamina cribrosa.

(iii) With Twigs from the Long Posterior Ciliary Arteries.-Sudakevitch (1947) quoted Meyer (1887) and Tichomiroff (1900) as describing the existence of anastomoses between twigs from the central artery to the trunk of the optic nerve and similar twigs from the long posterior ciliary arteries. Wybar (1956) stated that a dense pial arterial plexus surrounding the optic nerve was formed by branches from the posterior ciliary arteries, the ophthalmic artery, and the central retinal artery. Steele and Blunt (1956) and Beauvieux and Ristitch (1924), however, denied the existence of such anastomoses.

This was the commonest mode of anastomosis observed in the present series. Recurrent pial branches of the circle of Zinn ran backwards on the pia covering the optic nerve and anastomosed with pial branches of the central retinal artery (Figs 1, 16, 17, 18, 19, 21). This anastomosis was very occasionally intraneural, and in that case the intraneural branches and not the pial branches of the central artery took part in its formation. In one specimen an intra-orbital branch of the central artery anastomosed directly with a small lateral posterior ciliary artery. This anastomosis was seen on the dural sheath of the optic nerve.

The presence of these anastomoses was clearly demonstrated by fluid injected into the central retinal artery which filled the posterior ciliary artery from the eyeball side. 
(iv) With Pial Branches from the Ophthalmic Artery (Intraneural).-Vail (1948) described anastomoses between the fine branches of the central collateral branch of the central retinal artery, which runs in the centre of the optic nerve, with minute pial branches from the ophthalmic artery. Wexler (1950) and Wybar (1956) showed anastomoses between the intraneural branches of the central retinal artery and the pial arterial plexus. Wybar (1956) located these anastomoses within the substance of the optic nerve. Traquair (1949) on the other hand denied the existence of such anastomoses because the branches of the ophthalmic artery or of the central retinal artery which entered the optic nerve to supply it appeared to him to be end arteries.

In the present investigation, anastomoses between the intraneural branches of the central retinal artery and the pial branches of the ophthalmic artery were not often seen. Very rarely an anastomosis occurs between the intraneural branches of the central retinal artery and those of the collateral branches of the ophthalmic artery.

(v) With Pial Branches from the Ophthalmic Artery on the Pia.-Vail (1948) stated that minute branches from the ophthalmic artery anastomosed freely on the pia with recurrent or collateral branches arising from the central retinal artery at the point of entry into the dural sheath. Wybar (1956), as already mentioned, described the formation of a dense arterial network surrounding the optic nerve by the pial branches of the ophthalmic artery, the central retinal artery, and the posterior ciliary arteries. Beauvieux and Ristitch (1924), however, stated that there was no anastomosis between even the finest capillaries of the collateral branch of the central retinal artery and other pial branches from the ciliary or ophthalmic artery.

These types of anastomosis were the second most frequent variety seen in the present investigation. When coloured latex was injected into the ophthalmic artery after ligation of all its branches including the central artery of the retina, the collateral branches going to the nerve were left intact; the latex filled the central retinal artery in a disto-proximal direction, reaching the central retinal artery through anastomoses between its pial branches and those of the collateral branches of the ophthalmic artery (Figs 16, 17, 18, 19, 21, 23).

(vi) Pial Branches of the Central Retinal Artery Anastomosing with One AnotherThis was seen in several specimens in the present series, showing that the branches of the central retinal artery cannot be considered to be end arteries. This is contrary to the statements of Beauvieux and Ristitch (1924) and also of Traquair (1949), who, as already mentioned, considered the branches of the central retinal artery to be end arteries once they had entered the optic nerve. In the present series a branch from the intravaginal part of the central retinal artery was observed to anastomose with a branch from the intraneural part of the artery within the substance of the optic nerve. This agrees with the views of Wybar (1956).

Our studies of the anastomoses of the central retinal artery have led to the following conclusions:

(i) Numerous anastomoses exist between branches of the central artery 
of the retina and other branches of the ophthalmic artery, and also between individual branches of the central artery itself.

(ii) There are no anastomoses between the branches from the central artery and from the circle of Zinn in the region of the lamina cribrosa. Recurrent pial branches of the circle of Zinn do, however, anastomose frequently with pial branches of the central retinal artery.

(iii) The commonest site of anastomoses is over the pia. They occasionally occur within the substance of the optic nerve, and still more rarely on the dural sheath of the optic nerve.

(iv) Anastomoses established by the central artery are usually large enough to be seen with the naked eye and blood can easily pass through them into the central retinal artery as demonstrated by our various injection experiments. They are likely, therefore, to have considerable physiological significance.

\section{Summary}

Branches and anastomoses of the central artery of the retina have been studied in 106 human orbits. 100 specimens were injected with liquid Neoprene latex, and in the other six specimens the part of the optic nerve containing the central artery was sectioned serially. In two of the serially sectioned specimens, 3 per cent. prussian blue was injected in the artery and graphic reconstructions were made.

In the vast majority of the specimens, branches of variable size were seen to arise from the various parts of the central retinal artery with no constant pattern of origin. No branch arose at lamina cribrosa. These branches supplied the optic nerve to a variable degree extending from the eyeball to optic foramen, and also the dural sheath of the optic nerve. Very rarely the retina was supplied by a branch from the intraneural part of the artery in addition to the terminal branches.

Numerous anastomoses were observed between the branches of the central artery and the branches of the ophthalmic artery. These occurred most frequently between the pial branches of the central retinal artery and the recurrent pial branches of the circle of Zinn, the commonest site being on the pia covering the optic nerve. These anastomoses were usually large enough to allow the blood flow from one vessel to the other.

Our special thanks are due to Dr. Tulsi Dass, F.R.C.S., D.O.M.S. (Engl.), for his constant encouragement and guidance.

We also wish to express our thanks to Messrs. Du Pont De Nemours \& Co., Delaware, U.S.A., for supplying the Neoprene latex 571 and other accessories free of cost. We are grateful to Dr. W. J. Walker, who translated for us an article by Beauvieux and Ristitch (1924) from French. Finally we owe a debt of gratitude to Mr. Gurinder Singh Sekhon, photo-artist of Government Medical College, Patiala, for the photography, and to Dr. Inderbir Singh and Mr. R. C. Sharma for the various illustrations. 
Abbrevations Used in Figures: $\mathbf{C A R}=$ Central artery of retina. Col. br. $=$ Collateral branch; $\mathbf{C Z}=$ Circle of Zinn; $\mathbf{D S}=$ Dural sheath; $\mathbf{I} / \mathbf{N}=$ Intraneural part of $\mathbf{C A R} ; \mathbf{I} / \mathbf{O}=$ Intra-orbital part of CAR; I/V = Intravaginal part of CAR; LPCA = Lateral posterior ciliary artery; $\mathbf{M P C A}=$ Medial posterior ciliary artery; $\mathbf{O A}=$ Ophthalmic artery; $\mathbf{O N}=$ Optic nerve; $\mathbf{P C A}=\mathbf{P o s t e r i o r}$ ciliary artery; PPN = Point of piercing the optic nerve; PPS = Point of piercing the dural sheath.

\section{REFERENCES}

Abbie, A. A. (1938). Med. J. Aust., 2, 199.

BeAuvieuX, J., and RistiTCH, K. (1924). Arch. ophtal., 41, 352.

BEHR, C. (1935). v. Graefes Arch. Ophthal., 134, 227. (Cited by Kershner; Traquair; Wolff.)

Bignell, J. L. (1952). Trans. ophthal. Soc. Aust., 12, 105.

CoATs, G. (1905). Roy. Lond. ophthal. Hosp. Rep., 16, 262.

Duke-Elder, S. (1938). "Text-book of Ophthalmology", vol. 1, p. 139. Kimpton, London.

FrançoIs, J., and NeEtens, A. (1954). Brit. J. Ophthal., 38., 472.

(1956). Ibid., 40, 45.

- - - and Collette, J. M. (1955). Ibid., 39, 220.

GonIN, J. (1905). Ann. Oculist., 133, 167.

IGERSHEIMER, J. (1942). Ophthalmologica (Basel), 103, 230. (Cited by Vail; Traquair.)

KERSHNER, C. M. (1943). "Blood Supply of the Visual Pathway." Meador, Boston.

KuHNT, H. (1879). v. Graefes Arch. Ophthal., 25, pt. 3, p. 179.

LEBER, T. (1903). In "Graefe-Saemisch Handbuch der gesamten Augenheikunde", 2nd ed., Bd. 2, Abt. 2. Englemann, Leipzig. (Cited by Beauvieux and Ristitch; Wolff; Wybar; François and Neetens.)

Magitot, A. (1908). Thèse de Paris. Vigot Frères, Paris. (Cited by Beauvieux and Ristitch; Wolff; Wybar.)

MEYER, F. (1887). Morph. Jb., 12, 414. (Quoted by Sudakevitch, 1947.)

NeTTLESHIP, E. (1876). Brit. med.J., 1, 161 .

Parsons, J. H. (1906). "The Pathology of the Eye", vol. 3, p. 950. Hodder and Stoughton, London.

Rochon-Duvigneaud, A. (1933). “Recherches sur l'oeil et la vision chez les vertébrés”. Barnéoud, Laval. (Cited by François and Neetens.)

SAUTter, H., and SeITz, R. (1952). v. Graefes Arch. Ophthal., 152, 413.

SCHÄFER, E. A., and SYMINGTON, J. (1909). In "Quain's Elements of Anatomy”, 11th ed., vol. 3, pt. 2 , pp. 222, 248 . Longmans Green, London.

Singh, S., and DaSS, R. (1960). Brit. J. Ophthal., 44, 193.

STEele, E. J., and Blunt, M. J. (1956). J. Anat. (Lond.), 90, 486.

SUDAKEVITCH, T. (1947). Brit. J. Ophthal., 31, 738.

TichomiroFF, M. A. (1900). "Variations of the Arteries and Veins of the Human Body". Kiev. (Quoted by Sudakevitch, 1947.)

Traquar, H. M. (1949). "An Introduction to Clinical Perimetry", 6th ed., p. 299. Kimpton, London.

VAIL, D. (1948). Amer. J. Ophthal., 31, 1.

WeXIER, D. (1949). In C. Berens, "The Eye and Its Diseases", 2nd ed., p. 59. Saunders, Philadelphia.

Whitnall, S. E. (1932). "The Anatomy of the Human Orbit", 2nd ed., p. 306. Oxford University Press, London.

WolfF, E. (1939). Trans. ophthal. Soc. U.K., 59, 157. (1940). Ibid., 60, 69. (1954). "The Anatomy of the Eye and Orbit", 4th ed., pp. 121, 351. Lewis, London.

WYBAR, K. C. (1956). Brit.J. Ophthal., 40, 65. 